\title{
Ensino de História na perspectiva da Educação histórica: o caso da rede municipal de Curitiba
}

History teaching from the perspective of Historical Education: the case of Curitiba's Municipal Education System

Rosi Terezinha Ferrarini Gevaerd*

Faculdade São Braz

Resumo Em 2006, o ensino de história na Rede Municipal de Ensino de Curitiba adota a perspectiva da Educação Histórica, tomando como referência, especialmente, os estudos de Lee (2001), Barca (1998; 2004) e Schmidt (2001). Isso está expresso nas Diretrizes Curriculares (CURITIBA, 2006a) e nos Cadernos Pedagógicos - História (CURITIBA, 2006b). Em relação à formação continuada, mais especificamente em relação aos cursos oferecidos em parceria com a Universidade Federal do Paraná/Laboratório de Pesquisa em Educação Histórica (LAPEDUH), pode-se dizer que a sistemática adotada tem trazido contribuições valiosas, pois mudou a forma como o professor tem se relacionado com os conteúdos a serem trabalhados, na medida em que investiga as ideias tácitas dos alunos, seleciona diferentes fontes históricas, bem como solicita a produção de narrativas históricas aos alunos.

Palavras-chave: Ensino de História; Educação Histórica; Formação continuada.

\begin{abstract}
In 2006, the History teaching in Curitiba Education System adopted the Historical Education Perspective, drawing especially on the studies of Lee (2001), Barca (1998; 2004) and Schmidt (2001). That is displayed on the National Curriculum Guidelines (CURITIBA, 2006a) and on the Pedagogical Manuals - History (CURITIBA, 2006b). Regarding the continuing education, more specifically, regarding the courses offered in collaboration with the Federal University of Paraná/Research Laboratory on Historical Education (LAPEDUH), we can state that the systematics adopted has brought valuable contributions, since it has changed the way teachers relate to the contents to be worked with, as they investigate students' implicit ideas, select different historical sources, as well as request the creation of historical narratives from students.
\end{abstract}

KEYWORDS: History teaching; Historical Education; Continuing Education. 


\section{Introdução}

As investigações sobre cognição e ensino de história, mais conhecidas como investigações em Educação Histórica, foram produzidas, inicialmente, em países como Inglaterra, Estados Unidos e Canadá e têm se constituído como referência para que em Portugal, já há algum tempo, e no Brasil, mais recentemente, essa área de investigação passe a se consolidar. No dizer de Barca:

O ensino de História constitui-se hoje como um fértil campo de investigação, sendo objeto de pesquisa sob diversos ângulos que integram quer perspectivas diacrônicas quer a análise de problemáticas atuais do ensino específico.

É dentro desta segunda perspectiva que a investigação sobre cognição e ensino de História [...] tem-se desenvolvido com pujança em vários países [...]. Nestes estudos, os pesquisadores têm centrado a sua atenção nos princípios, fontes, tipologias e estratégias de aprendizagem em História, sob o pressuposto de que a intervenção do professor na qualidade das aprendizagens exige um conhecimento sistemático das idéias históricas dos alunos, por parte de quem ensina (e exige também um conhecimento das idéias históricas destes últimos).

A análise destas idéias implica um enquadramento teórico que respeite a natureza do saber histórico e que deve refletir-se, do mesmo modo, na aula de História. (BARCA, 2005, p. 15).

Nessa perspectiva, a educação histórica tem se constituído a partir de uma fundamentação teórica específica, sendo que suas áreas basilares são: a Epistemologia da História, a Metodologia de Investigação em Ciências Sociais e a História.

Os objetivos centrais das investigações no domínio da cognição histórica têm procurado:

$$
\begin{aligned}
& \text { - compreender os processos cognitivos dos sujeitos ao pensarem } \\
& \text { História; } \\
& \text { - examinar as relações entre as ideias tácitas (ideias que os alunos } \\
& \text { constroem a partir de suas vivências) e os conceitos históricos; } \\
& \text { - explorar a compreensão dos alunos quanto aos conceitos históricos, } \\
& \text { quer de natureza substantiva quer de natureza epistemológica (por } \\
& \text { exemplo, interpretação de fontes). (BARCA; GAGO, 2001, p. 242). }
\end{aligned}
$$

Nesse sentido, o ensino de história na perspectiva da educação histórica tem assumido um papel importante na Rede Municipal de Ensino de Curitiba (RME), pois segundo Barca:

Em História, a aprendizagem é orientada para uma leitura contextualizada do passado a partir da evidência fornecida pelas variadíssimas fontes. A História não trata de certezas sobre um passado considerado fixo até que novos factos sejam descobertos; existem construções historiográficas diferentes, por vezes a responder a perguntas muito próximas, mas com enfoques diferentes. Numa sociedade aberta, torna-se cada vez mais óbvia esta característica da História - a de que não se aceita apenas "uma grande narrativa" 
acerca do passado -, já que os historiadores podem produzir narrativas divergentes, fruto de perspectivas diferenciadas sobre as mesmas fontes ou situações. (BARCA, 2006, p. 95).

Tomando como referência os pressupostos teóricos e metodológicos da Educação histórica, apresenta-se, neste trabalho, alguns resultados das atividades que têm sido desenvolvidas no âmbito da Rede Municipal de Ensino de Curitiba, mais especificamente, como foi se constituindo o ensino de história nessa rede de ensino, em seguida a concepção da Educação Histórica assumida, em 2006, nas Diretrizes Curriculares (CURITIBA, 2006a), bem como no Caderno Pedagógico de História (CURITIBA, 2006b), e, finalmente, alguns aspectos da formação continuada adotada a partir desses documentos oficiais, mais especificamente, em relação aos cursos oferecidos em parceria com a Universidade Federal do Paraná e Laboratório de Pesquisa em Educação Histórica (LAPEDUH).

\section{Ensino de história na RME: breve histórico}

A atuação do poder municipal no setor educacional tomou uma forma mais concreta na cidade de Curitiba em 1955 (CURITIBA, 1993, p.6, apud GEVAERD, 2009 , p.151). Nesse contexto, a competência dos municípios se restringia à construção de salas de aula, pois esta era a preocupação dos administradores da época.

Nesse período, inicia-se, em nível nacional, a implantação de uma experiência de ensino integrada, os Estudos Sociais, sendo que a principal preocupação desse ensino, segundo o PABAEE - Programa de Assistência Brasileiro - Americana de Ensino Elementar (1953-1956), citado por Schmidt (1985, p. 210), era: "estudar o mecanismo das relações humanas, vistas sob o aspecto das relações das pessoas com as pessoas, das pessoas com as instituições, das pessoas com os produtos”. A partir dessas questões ocorrem mudanças nos programas curriculares, mais especificamente nas matérias que tratavam "das atividades e dos feitos do homem: geografia e história".

Em Estudos Sociais, a relevância era dada aos "aspectos e maneiras de vida do homem, ao trabalho de cooperação entre os homens, ao uso do ambiente para satisfação das necessidades básicas, aos costumes, instituições, herança social, passado histórico de um povo". Tendo estas questões como pressupostos, o ensino de Estudos Sociais tinha como objetivo "levar a criança à compreensão dos fatos e situações de vida, ajustando-a ao seu meio, integrando-se nos grupos a que vem pertencer, convivendo com os outros, resolvendo e vencendo seus problemas" (SCHMIDT, 1985, p. 211).

Como nesses primeiros anos de "experimentação pedagógica" a função do município de Curitiba restringia-se à expansão do setor da rede física, as escolas municipais, a partir das orientações pedagógicas fornecidas pelo Estado, organizavam seu planejamento tendo como ponto principal a relação das matérias em um tema central, a chamada Unidade de Trabalho ou Unidade de Experiência (GEVAERD, 2003, p. 87). 
Em 1974, a Diretoria de Educação da Prefeitura Municipal de Curitiba estabelece as Diretrizes de Ensino de $1^{\circ}$ grau - Bases Legislativas. Este é o primeiro documento que aponta uma sistematização da mantenedora em forma de currículo, no qual estava estabelecida a linha metodológica, destacando a importância da escola e do trabalho do professor na condução do aluno ao desenvolvimento de valores como socialização, integração e liberdade, levando-o a compreender que "ser mais é ser livre e ser livre é estar inserido". Para tanto, a tarefa educativa reside em utilizar os mais variados métodos, técnicas e estratégias para fazer com que o "indivíduo inserido seja útil à comunidade" (CURITIBA, 1974, p. 1 apud GEVAERD, 2003, p. 99-101).

Nessas Diretrizes e nos Planos Curriculares organizados durante a década de 1970 a história permanecia tendo como linha norteadora a história política, contemplando conteúdos sobre o Município, o Estado e o País, mantendo-se como um ensino voltado para a construção da nacionalidade e regionalidade (GEVAERD, 2009, p. 156).

Com o processo de redemocratização da sociedade brasileira, na década de 1980, ocorreram mudanças no âmbito educacional. Entre as questões consideradas relevantes nas discussões, os Estudos Sociais ocupavam lugar de destaque, considerando-se que o ensino de História e Geografia havia sofrido um grande esvaziamento teórico com a introdução dos Estudos Sociais e da Integração Social. Neste sentido, a discussão girava em torno da retomada das disciplinas História e Geografia. Na RME, este processo se iniciou envolvendo professores e professoras de $5^{\mathrm{a}}$ a $8^{\mathrm{a}}$ série, bem como das séries iniciais, concretizando uma nova proposta curricular em 1987, divulgada no documento Jornal da Escola Aberta, com a finalidade de subsidiar as escolas de $1^{\mathrm{a}}$ a $4^{\mathrm{a}}$ séries na discussão e reflexão para a "organização curricular tendo como eixo norteador os conteúdos de História e Geografia” (CURITIBA, 1987, p. 17-20 apud GEVAERD, 2009, p. 156).

Considerando os avanços nos meios acadêmicos, na década de 1980, referentes ao ensino de história, busca-se inseri-los no ensino de $1^{\circ}$ grau. Para tanto, a partir de 1989 dá-se prosseguimento a essas reflexões e, em 1992, concretiza-se, na rede municipal, uma proposta no documento "Currículo Básico: compromisso permanente para a melhoria da qualidade do ensino na escola pública" (CURITIBA, 1989-1992), com encaminhamentos específicos para a História e para a Geografia (GEVAERD, 2009, p. 157-158).

A história resgata, assim, sua especificidade enquanto ciência, e toma como fio condutor um ensino renovado de história que possibilita ao aluno o acesso ao conhecimento historicamente acumulado e a reflexão crítica desse conhecimento, o que lhe permite situar-se no seu tempo e em sua sociedade, estabelecendo relações com outras sociedades em outros tempos (GEVAERD, 2009, p. 158).

A partir de 1997, inicia-se, na rede municipal, um processo gradativo de implantação da organização do ensino em Ciclos de Aprendizagem, sendo que o ciclo I corresponde à $1^{\mathrm{a}}$ e 2 série, ciclo II à $3^{\mathrm{a}}$ e $4^{\mathrm{a}}$ série. Para tanto, a SME possibilita ações que visam subsidiar as mudanças no fazer pedagógico das escolas, organizan- 
do momentos de reflexões e discussões com a participação de seus representantes na elaboração do documento: A escola organizada em ciclos de aprendizagem: Diretrizes Curriculares - em discussão, com o objetivo de contribuir com as escolas nesse processo de construção coletiva. Em história, os objetivos foram estabelecidos tendo como perspectiva o que o aluno necessita "para compreender a realidade em que vive" (CURITIBA, 1997-2000, p. 1-83, apud GEVAERD, 2009, p. 159).

Em 2006, a SME propõe uma nova reorganização curricular, que se concretizou no documento: Diretrizes Curriculares para a Educação Municipal de Curitiba (2006a). A concepção de história toma como objeto do ensino "as formações sociais, bem como as relações sociais que nelas se estabelecem" (CURITIBA, 2006a, p. 152 apud GEVAERD, 2009, p. 159).

A concepção adotada apresenta mudanças, na medida em que assume como pressupostos teóricos e metodológicos os estudos na perspectiva da educação histórica tomando como referência, especialmente, os estudos de Lee (2001), Barca (1998) e Schmidt (2001).

Entre outras questões, na referida concepção adota-se os princípios propostos por Barca (1998), na medida em que para essa autora o ensino de História não deve ser a "regurgitação do passado", mas o professor deve estimular o pensamento crítico de seus estudantes, adotando alguns procedimentos específicos, como investigar as ideias que eles já possuem, possibilitando que reflitam sobre diferentes hipóteses em História; exercitar com seus alunos a seleção das diferentes respostas historiográficas para aquele contexto histórico; estimulá-los a construírem novas hipóteses investigativas, ou seja, novas questões de investigação (CURITIBA, 2006a, p. 152).

Ressalta-se, também, que o professor, além de falar sobre acontecimentos do passado, deve oportunizar situações de aprendizagem para que ocorra a interpretação desse passado, o que poderá ser efetivado a partir de um trabalho com documentos históricos. Esta metodologia ajuda o aluno a conhecer os conceitos substantivos da história a partir de diferentes fontes; estimula-o na observação, auxiliando-o na reflexão histórica; bem como propicia-lhe o entendimento do sentido da História (CURITIBA, 2006a, p. 153).

A partir de Schmidt (2001, p. 59), assume-se que é fundamental o professor oportunizar "situações para que o aluno comece a pensar historicamente" e que o conhecimento histórico deve ser ensinado para que o aluno, tenha "condições de participar do processo do fazer, do construir a História” (CURITIBA, 2006a, p. 153-154).

Com base em Lee (2005, p. 1-2), assume-se que não se pretende transformar os estudantes em pequenos historiadores. No entanto, cabe ao professor auxiliar o aluno a compreender que a história está em constante transformação e que existem diferentes interpretações e explicações históricas. Além disso, o professor deve propiciar um processo de reflexão para que os estudantes consigam perceber que as interpretações históricas são construídas a partir das evidências e que "está na natureza da História haver diversas versões do passado", mas que, apesar disso, a História não é "apenas uma questão de opinião" (CURITIBA, 2006a, p. 154). 
A partir da concepção assumida, os objetivos e conteúdos foram propostos tomando como ponto de partida os eixos articuladores: cultura, identidade e cidadania. Eixos que partem do pressuposto de que são conceitos, no dizer de Schmidt (2001, p. 61), "criados, datados, constituem-se historicamente, em meio a mudanças e permanências nos diferentes tempos e nos diferentes espaços, portanto, possuem uma história" (CURITIBA, 2006a, p. 155, apud GEVAERD, 2009, p. 21-22).

Cabe ressaltar que durante o processo da elaboração das diretrizes curriculares foram organizados encontros com os professores da RME para discussão da proposta inicial. As sugestões advindas dos professores foram incorporadas na medida em que estivessem de acordo com a concepção assumida. Após a finalização da mesma, foram organizados encontros para a sua implementação.

Após esse processo, foram elaborados os Cadernos Pedagógicos para as diferentes áreas do conhecimento ${ }^{1}$, entre eles, o de História. No dizer da Secretária da Educação, Eleonora Bonato Fruet "Trata-se de um instrumento paradidático, que vem compor o conjunto de recursos de que dispõem as equipes de nossas escolas para o planejamento de processos de ensino" (FRUET, 2006b, p. 3).

\section{Caderno Pedagógico de História: possibilidades de ensino na perspectiva da educação histórica}

O Caderno Pedagógico de História foi elaborado tendo como finalidade "contribuir para a prática pedagógica", mas com a ressalva de que a proposta é uma das possibilidades de articulação dos objetivos e conteúdos, pois existem muitas outras (CURITIBA, 2006b, p. 111).

Os encaminhamentos propostos são indicados para a iniciação histórica referente aos Ciclos I e II do Ensino Fundamental, no entanto, servem de subsídios para as demais fases de escolarização.

Para a elaboração do caderno, adotou-se a perspectiva da Educação Histórica, mais especialmente os pressupostos da aula-oficina de Isabel Barca (2004), a saber: investigar os conhecimentos prévios dos estudantes; trabalhar com fontes históricas; solicitar a produção de narrativas históricas pelos alunos.

Para tanto, sugere-se que o professor, inicialmente, deve partir do conhecimento que os estudantes já possuem, ou seja, a investigação dos conhecimentos prévios ou tácitos, aqueles conhecimentos que os alunos adquirem em suas experiências sociais, isto é, junto aos seus familiares, no processo de escolarização, na mídia, entre outras situações cotidianas (CURITIBA, 2006b, p. 9). Essa investigação pode ser por meio de uma "chuva de ideias". De posse das ideias prévias, o professor pode classificá-las em ideias do passado, ideias do presente, bem como ideias que se relacionam - presente e passado. De posse da categorização dos conhecimentos prévios, o professor organiza a sua mediação didática quando então problematiza, analisa e explora os conteúdos escolares propostos a partir do uso de fontes históricas. 
Após a mediação didática, o professor solicita que o aluno expresse o que aprendeu por meio da produção de narrativa histórica, que pode ser realizada por meio de: desenhos, pequenas narrativas, narrativas mais elaboradas, narrativas mais complexas, de acordo com o nível de escolarização (CURITIBA, 2006b, p. 11).

Para finalizar, o professor avalia o que o aluno conseguiu expressar sobre o conteúdo escolar trabalhado. Deve observar "se o estudante incorporou: as novas ideias na construção de sua argumentação; novos conceitos; se já incorporou o uso do documento em sua narrativa” (CURITIBA, 2006b, p. 11).

Todos os professores que atuavam em sala de aula receberam um kit com os exemplares dos cadernos das diferentes áreas do conhecimento. Além disso, foram organizados encontros que propiciaram a discussão teórica sobre a sistemática adotada, bem como atividades práticas que possibilitaram o desenvolvimento do trabalho proposto. Pode-se dizer que o caderno tem sido material de referência na organização dos encontros de assessoramentos nas escolas e Núcleos Regionais, nos cursos de formação continuada, bem como material utilizado pelos professores em suas aulas de história.

\section{Formação continuada na perspectiva da Educação histórica}

A Secretaria Municipal da Educação de Curitiba oferece diferentes modos de formação continuada a seus profissionais, entre elas: assessoramentos, reuniões, palestras, seminários, cursos com a finalidade de promover discussões teóricas e metodológicas aos profissionais do ensino fundamental da RME de acordo com as necessidades apresentadas.

Nesses encontros, têm-se privilegiado discussões sobre o que é história; fontes históricas; narrativa histórica, tomando como referência especialmente os estudos de Schmidt; Cainelli (2009) e Rüsen (2012).

Dentre os cursos propostos, destaca-se o oferecido aos docentes e pedagogos que atuam em escolas que atendem aos alunos do $6^{\circ}$ ao $9^{\circ}$ ano. Os cursos oferecidos, desde 2010, como extensão universitária, contam com a parceria do Laboratório de Pesquisa em Educação Histórica - LAPEDUH, integrado ao Programa de PósGraduação em Educação (PPGE) da Universidade Federal do Paraná (UFPR), sob a docência da Profa. Dra. Maria Auxiliadora Moreira dos Santos Schmidt.

A proposta desses cursos insere-se no contexto das ações referentes ao projeto "Aprender a ler e aprender a escrever em História", aprovado como bolsa produtividade Cnpq/2006. Assim como, está circunscrito no conjunto de atividades que a coordenadora, Maria Auxiliadora Moreira dos Santos Schmidt, e a vice-coordenadora, Tânia Maria Figueiredo Braga Garcia, vêm realizando como líderes do grupo de Pesquisa Cultura, saberes e educação histórica, certificado pela UFPR.

Esses cursos têm propiciado um aprofundamento teórico e prático aos participantes, com o objetivo de ampliar as reflexões sobre as questões relacionadas às investigações na perspectiva da Educação Histórica, concepção assumida nas Dire- 
trizes Curriculares da Rede Municipal de Ensino de Curitiba (2006a). Um dos princípios gerais norteadores da metodologia proposta nesses cursos é a possibilidade de superação da escola como instituição reprodutora e disciplinadora e a sua apreensão como espaço da experiência social, onde os sujeitos envolvidos nas relações pedagógicas podem agir no sentido da transformação de suas práticas sociais, desde que existam condições objetivas para uma nova relação entre os sujeitos e destes com os saberes escolares (DUBET; MARTUCELLI, 1997; CHARLOT, 2000). Nesse sentido, os profissionais envolvidos têm a possibilidade de atuar como investigadores de sua ação pedagógica.

Entre os princípios específicos da Educação Histórica, que fundamentam a metodologia adotada, está a proposta da Aula Oficina (BARCA, 2004), na qual os professores encontram subsídios para investigações em sala de aula; as propostas de investigação em Educação Histórica, seja pesquisando os conceitos substantivos em História, como os trabalhos de Lee (2003); seja na investigação da narrativa como conceito de segunda ordem na História, sugeridos nos trabalhos de Barca e Gago (2001), assim como o trabalho com fontes históricas na perspectiva de Schmidt e Cainelli (2009).

Para a organização dos cursos, têm-se priorizado diferentes temáticas. Em 2010, questões sobre narrativa histórica, patrimônio material e imaterial, sob o título: Patrimônio e narrativa histórica no ensino de história; em 2011, questões sobre fontes históricas disponíveis na internet, sob o título: $\mathrm{O}$ trabalho com fontes e a produção de narrativas em aulas de história: mediação das tecnologias da informação e da comunicação.

Em 2012 e 2013, a parceria foi ampliada com a participação do Arquivo Público do Paraná. Nesse ano, o curso recebeu o título: $\mathrm{O}$ trabalho com arquivos e a literacia histórica: questões teóricas e práticas; durante o qual professores e alunos tiveram acesso a diferentes fontes históricas, tanto de forma presencial como as disponíveis no site do referido arquivo.

Entre os objetivos do curso, prioriza-se a orientação para a produção, pelos participantes, de artigo científico, com a finalidade de apresentação em eventos de cunho local, nacional e/ou internacional, bem como a publicização dos mesmos. Para a orientação dos trabalhos, optou-se pela metodologia da pesquisa colaborativa na perspectiva de Ibiapina (2008), na medida em que essa autora considera que essa forma de pesquisa é "atividade de co-produção de saberes, de formação, reflexão e desenvolvimento profissional, realizada interativamente por pesquisadores e professores com o objetivo de transformar determinada realidade educativa" (2008, p.31).

Como resultados concretos da participação dos professores e professoras durante os cursos, foram realizadas comunicações de seus trabalhos em diferentes eventos, conforme quadro abaixo: 


\begin{tabular}{|c|c|c|c|}
\hline Ano & Evento & $\begin{array}{c}\text { Número de } \\
\text { trabalhos } \\
\text { apresentados }\end{array}$ & $\begin{array}{c}\text { Número de } \\
\text { professores/as } \\
\text { envolvidos/as }\end{array}$ \\
\hline \multirow{2}{*}{2010} & $\begin{array}{l}\text { X Jornadas Internacionais de Educação } \\
\text { Histórica - UEL }\end{array}$ & 6 & 7 \\
\hline & $\begin{array}{l}\text { 3o Seminário de Educação Histórica - } \\
\text { LAPEDUH/UFPR }\end{array}$ & 6 & 7 \\
\hline \multirow{2}{*}{2011} & $\begin{array}{l}\text { 4o Seminário de Educação Histórica - } \\
\text { LAPEDUH/UFPR }\end{array}$ & 7 & 7 \\
\hline & $\begin{array}{l}\text { XIIJornadas Internacionais de Educação } \\
\text { Histórica - LAPEDUH/UFPR }\end{array}$ & 8 & 10 \\
\hline \multirow{2}{*}{2012} & $\begin{array}{l}\text { 5o Seminário de Educação Histórica - } \\
\text { LAPEDUH/UFPR }\end{array}$ & 8 & 12 \\
\hline & $\begin{array}{l}\text { 60 Seminário Brasileiro de Educação } \\
\text { Histórica - LAPEDUH/UFPR }\end{array}$ & 7 & 9 \\
\hline
\end{tabular}

Em 2010 e 2011, o curso era oferecido no período da noite, pois a RME não garantia o dia de permanência concentrada, nesse sentido, somente sete (07) professores tinham disponibilidade para participar do curso. Sendo que todos apresentaram seus trabalhos nos eventos oferecidos nesses anos, a saber: em 2010, a X Jornadas Internacionais de Educação Histórica, sediada na Universidade Estadual Londrina (UEL) e o 30 Seminário de Educação Histórica, organizado pelo LAPEDUH/UFPR. Alguns trabalhos apresentados em 2010: Educação histórica e ensino de história: as ideias de jovens escolarizados sobre a segunda guerra mundial (J. A. O.); Unidade temática investigativa como procedimento na construção da narrativa histórica em sala de aula (C. S. C.); Comunidades quilombolas no Paraná: ação investigativa em aulas de história (A. C. M.; L. H.X.), entre outros.

Em 2011, os sete (07) professores inscritos no curso participaram do $4^{\circ} \mathrm{Se}-$ minário de Educação Histórica, sediado pela UFPR/LAPEDUH. Alguns trabalhos apresentados em 2011: História e juventude: diários pessoais e blogs como espaço de memória (C. S. C.); Como trabalhar com vídeos de internet: algumas possibilidades (J.A. O.), entre outros.

Em 2012, a RME passa a garantir o dia de permanência concentrada, com isso possibilita um maior número de professores a participar do curso, bem como dos eventos organizados pelo LAPEDUH/UFPR, a saber: as XII Jornadas Internacionais de Educação Histórica, com a participação de dez (10) professores, e o $5^{\circ}$ Seminário de Educação Histórica, com a comunicação de doze (12) professores. Alguns trabalhos apresentados: Arquivos e fonte histórica em aulas de história: repressão em Curitiba durante a segunda guerra mundial (C. C. M. S.; M. S.); O Arquivo Público na sala de aula: revolução industrial, nascimento do movimento operário e a greve de 1917 em Curitiba a partir do estudo de fontes históricas (G.H.T.; M. G.), entre outros. 
Em 2013, o LAPEDUH sedia o 6 Seminário Brasileiro de Educação Histórica, sendo que nove (09) professores apresentaram seus trabalhos, entre eles: Indígenas na cidade: silêncio ou invisibilidade (P. L. B.); Nazismo no Brasil: a produção de narrativas críticas aos documentos (S. L. F.), entre outros.

Além da participação em eventos, foi proposto aos professores organizar uma metodologia para ser divulgada no site do Portal de Educação Histórica². O Portal foi implantado pelo LAPEDUH, do Programa de Pós-Graduação em Educação, da Universidade Federal do Paraná, sob a coordenação da Professora Maria Auxiliadora Schmidt, e conta com a participação de professores da escola básica e pesquisadores do LAPEDUH. Até o momento, duas produções, da professora Cláudia Caramez e do professor Jackes Alves de Oliveira, estão disponíveis para consulta. Segundo as palavras do referido professor, "O desafio de criar uma metodologia para se trabalhar com os vídeos de internet foi muito gratificante. Assim como em qualquer campo de trabalho, o professor sente-se vitorioso por superar desafios, mesmo que eles venham a todo momento" (OLIVEIRA, 2011, p. 8).

\section{Considerações finais}

Algumas considerações podem ser apresentadas em relação à concepção adotada nas Diretrizes Curriculares, a partir da perspectiva da Educação Histórica; observa-se que, de modo geral, mudou a forma como o professor tem se relacionado com os conteúdos a serem trabalhados, na medida em que, ao partir das ideias tácitas dos alunos, organiza a sua ação didática buscando diferentes fontes históricas, tendo em vista as carências de orientação apresentadas pelos alunos.

Além disso, pode-se dizer que ocorreu, por parte dos professores, a incorporação da ideia de narrativa histórica como uma maneira de aprender e ensinar história, pois, como apontado por Gevaerd (2009, p. 67) a partir dos estudos de Husbands (2003, p. 51), na aprendizagem histórica a narrativa não é um fim em si mesma, mas um meio para determinado fim, isto é, para a produção de uma compreensão sobre o passado. Além disso, segundo Rüsen (1993), a aprendizagem que constitui a consciência histórica vem em destaque nas narrativas, ou seja, no ato de contar histórias, pois esta é uma forma coerente de comunicação e porque trata da identidade histórica tanto do comunicador como do receptor.

Em relação à formação continuada, mais especificamente em relação aos cursos oferecidos em parceria com o LAPEDUH/UFPR, pode-se dizer que a sistemática adotada tem trazido contribuições valiosas tanto para os professores envolvidos como para os alunos, na medida em que esses profissionais estão tendo acesso às discussões trazidas por pesquisadores nacionais e internacionais que têm se preocupado com o ensino e aprendizagem no âmbito da Educação Histórica.

Para finalizar, pode-se dizer que o ensino de história na perspectiva da educação histórica tem assumido um papel importante na RME, pois os professores têm percebido que é fundamental levar para a sala de aula os procedimentos metodológicos usados pelos historiadores em situações de ensino e aprendizagem. 


\section{Referências}

BARCA, I. Verdade e perspectivas do passado na explicação em história: uma visão pós-desconstrucionista. Revista O Estudo da História - O ensino da História: problemas da didáctica e do saber histórico, Lisboa, A. P. H. Associação de Professores de História, n. 3, 1998, p. 163173.

Aula Oficina: do projecto à avaliação. In: BARCA, I. (Org.). Para uma educação histórica com qualidade. Actas das IV Jornadas Internacionais de Educação Histórica. Braga: Centro de Estudos em Educação e Psicologia, Universidade do Minho, 2004. p. 131-144.

Educação histórica: uma nova área de investigação. In: ARIAS NETO, J. M. (Org.). Dez anos de pesquisas em ensino de história. Londrina: AtritoArt, 2005. p. 15-25.

Literacia e consciência histórica. Educar em Revista. Curitiba, n. 164, p. 93-112, 2006.

BARCA, I.; GAGO, M. Aprender a pensar em história: um estudo com alunos do 6.o ano de escolaridade. Revista Portuguesa de Educação, Portugal, v. 14, n. 1, p. 239-261, 2001.

BARTON, K. It Wasn't a Good Part of History: National Identity and Students' Explanations of Historical Significance. Teachers College Record, New York, v. 99 n. 3, p. 478-513, 1998.

Explicações da significância histórica em alunos do Ensino Básico. O Estudo da História, n. 4, p. 207-236, 2001.

CHARLOT, B. Da relação com o saber: elementos para uma teoria. Porto Alegre: Artes Médicas, 2000.

CURITIBA. Diretrizes de Ensino de $1^{\circ}$ Grau - Bases Legislativas - 1974. In: CURITIBA. Currículos - Escolas. Prefeitura Municipal de Curitiba. Departamento do Bem-Estar Social. Diretoria de Educação. Divisão de Estudos e Pesquisas. Curitiba, 1974. Datilografado.

30 anos de educação nos 300 anos de Curitiba. Prefeitura Municipal de Curitiba. Secretaria Municipal da Educação. Departamento de Informações, Estudos e Pesquisas Educacionais. Divisão de Pesquisas Educacionais. Curitiba, [1993].

Escola Aberta. Jornal da Secretaria Municipal da Educação. Secretaria Municipal da Educação de Curitiba. Curitiba, Ano IV, n. 9, abr./maio 1987.

Currículo Básico: compromisso permanente para a melhoria da qualidade do ensino na escola pública. Prefeitura Municipal de Curitiba. Secretaria Municipal da Educação. Curitiba, 1989-1992.

A escola organizada em ciclos de aprendizagem: Diretrizes Curriculares - em discussão. Prefeitura Municipal de Curitiba. Secretaria Municipal da Educação. Curitiba, gestão 1997-2000.

Diretrizes Curriculares para a Educação Municipal de Curitiba. Prefeitura Municipal de Curitiba. Secretaria Municipal da Educação. V. 3. Ensino Fundamental. Curitiba: SME, 2006a.

Caderno Pedagógico - História. Prefeitura Municipal de Curitiba. Secretaria Municipal de Curitiba: SME, 2006b.

DUBET, F.; MARTUCELLI, D. En la escuela: sociologia de la experiencia escolar. Barcelona: Losada, 1997.

FORQUIN, J. Escola e cultura: as bases sociais e epistemológicas do conhecimento escolar. Porto Alegre: Artes Médicas, 1993

FREIRE, P. A importância do ato de ler, em três artigos que se completam. São Paulo: Cortez, 1997 
FRUET, E. B. Apresentação. In: Caderno Pedagógico - História. Prefeitura Municipal de Curitiba. Secretaria Municipal de Curitiba: SME, 2006b, p. 3.

GEVAERD, R. T. F. História do Paraná: a construção do código disciplinar e a formação de uma identidade paranaense. 2003. Dissertação (Mestrado em Educação) - Programa de Pós-Graduação de Educação, Linha de Pesquisa Cultura, Escola e Ensino, Setor de Educação - Universidade Federal do Paraná, Curitiba, 29 ago. 2003.

A narrativa histórica como uma maneira de ensinar e aprender história: o caso da história do Paraná. Tese (Doutorado em Educação) - Programa de Pós-Graduação de Educação, Linha de Pesquisa Cultura, Escola e Ensino, Setor de Educação - Universidade Federal do Paraná, Curitiba, 30 mar. 2009.

HUSBANDS, C. R. What is history teaching? Language, ideas, and meaning in learning about the past. Buckingham: Open Press University Press, 2003.

IBIAPINA, M. L. M. Pesquisa colaborativa: investigação, formação e produção de conhecimentos. Brasília: Líber Livro Editora, 2008.

LEE, P.; ASHBY, R. Progression in historical understanding among students ages 7-14. In: STEARNS, P. N.; SEIXAS, P.; WINEBURG, S. (Eds.). Knowing, teaching and learning History: national and international perspectives. New York: New York University Press, 2000, p. 199-222.

LEE, P. Progressão da compreensão dos alunos em História. In: BARCA, I. (Org.). Perspectivas em educação histórica: Actas das Jornadas Internacionais de Educação Histórica. Minho: Universidade do Minho, 2001.

'Walking Backwards into Tomorrow'. Historical Consciousness and Understanding History. International Journal of Historical Learning, Teaching and Research. v. 4, n. 1, p. 1-46, 2002.

. Nós fabricamos carros e eles tinham que andar a pé. In: SEGUNDAS JORNADAS INTERNACIONAIS DE EDUCAÇÃO HISTÓRICA: PERSPECTIVAS EM EDUCAÇÃO HISTÓRICA, 2, 2002, Braga. Actas... Braga: Universidade do Minho. Centro de Estudos em Educação e Psicologia, 2003. p. 19-36.

Putting Principles into Practice: Understanding History. In: DONOVAN, M. S., BRANSFORD, J. D. How Students Learn History, Matematics, and Science in the Classroom. Washington: The National Academies Press, 2005. p. 31-78.

. Por que aprender História? Educar em Revista, Curitiba, v. 42, p. 19-42, 2011.

. "Nós fabricamos carros e eles tinham que andar a pé": compreensão das pessoas do passado. In: BARCA, I. (Org.). Educação histórica e museus. Actas das Segundas Jornadas Internacionais de Educação Histórica. Braga: Lusografe, 2003. p. 19-36.

Educação histórica. Opinião. Associação de Professores de História. Disponível em: <http//www.aph.pt/opinião/opinião> Acesso em: 06 jun. 2005.

LE GOFF, J. História e Memória. Campinas: UNICAMP, 1992.

MARTinS, E. R. A História Pensada: teoria e métoda na historiografia européia do século XIX. São Paulo: Contexto, 2010.

OLIVEIRA, J. Como trabalhar com vídeos de internet. In: Portal de Educação Histórica. Disponível em: <http://www.educahis.ufpr.br/docs/59cc0bbb25dda87043d500a5eb03cc13.pdf>. Acesso em: 10 jun. 2012.

RÜSEN, J. Experience, interpretation, orientation: three dimensions of historical learning. In: DUVENAGE, P. (Ed.). Studies in metahistory. Pretoria: Human Sciences Research Council, 1993. 
O livro didático ideal. In: SCHMIDT, M. A.; BARCA, I.; MARTINS, E. R. Jörn Rüsen e o ensino de História. Curitiba: Ed. UFPR, 2010. p. 109-128.

Aprendizagem histórica: fundamentos e paradigmas. Curitiba: W.A. Editores, 2012.

SCHMIDT, M. A. M. S. O porquê dos estudos sociais: implicações histórico-sociais, políticas, econômicas. História: Questões e debates, Curitiba, Ano 6, n. 11, 1985.

A formação do professor de História e o cotidiano da sala de aula. In: BITTENCOURT, C. (Org.). O saber histórico na sala de aula. São Paulo: Contexto, 2001.

SCHMIDT, M. A.; CAINELLI, M. Ensinar história. São Paulo: Scipione, 2009.

SEIXAS P Scheweigen! Die Kinder! or, Does Postmodern History Have a Place in the Schools?. In: STEARNS, P. N.; SEIXAS, P.; WINEBURG, S. (Eds.). Knowing, teaching and learning History: national and international perspectives. New York: New York University Press, 2000. 482 p. p. 19-37.

\section{Notas}

${ }^{1}$ Em 2006, as equipes das áreas do conhecimento do Departamento de Ensino Fundamental - Gerência de Currículo elaboraram os Cadernos Pedagógicos. Disponíveis para download no site http://www.cidadedoconhecimento.org.br/cidadedoconhecimento, link Cadernos Pedagógicos.

${ }^{2}$ Site http://www.educahis.ufpr.br

* Professora doutora da Faculdade São Braz, Curitiba, Paraná, Brasil.

\section{Correspondência}

Rosi Terezinha Ferrarini Gevaerd - Prefeitura Municipal de Curitiba, Secretaria Municipal da Educação de Curitiba. Avenida João Gualberto, 526, 7o andar, Torre A, Alto da Glória. CEP: 80060-010 - Curitiba, Paraná - Brasil.

E-mail: rosigevaerd@gmail.com

Recebido em 02 de junho de 2015

Aprovado em 06 de agosto de 2015 